\title{
OUTCOME OF RADICAL CYSTECTOMY WITH URINARY DIVERSION AT NICRH, BANGLADESH
}

\author{
MD. SHAWKAT ALAM ${ }^{1}$, HOWLADER FAZLUL KARIM ${ }^{2}$, MD. MONOWARUL ISLAM ${ }^{3}$, MD. SIDDIQUR \\ RAHMAN $^{4}$, SK. AMIRUL ISLAM ${ }^{5}$, MA SALAM ${ }^{6}$
}

\begin{abstract}
Introduction: Radical Cystectomy $(R C)$ is an effective surgical procedure for muscle invasive bladder cancer (MIBC). 5 years disease free survival after RCs are PT2 - 81\%, PT3a - 68\%, PT3b-47\%, PT4a - 44\% respectively, Stein et al, 2001[1]. In this study early surgical \& oncological outcome have been assessed.

Patients \& methods: A total of 24(N) patients underwent radical cystectomy with urinary diversion between December 2013 to June 2016. Age ranges from 41-69 years. Indications were T2HG for twenty cases and T1HG for four cases. Among the T1 tumours, one had early recurrence, one had numerous tumours and two had multiple tumours with concomitant CIS. Urinary diversion methods were: Orthotopic lleal neobladder-1, Ileal conduit-20, Cuteneous Ureterostomy -3 (2 due to unhealthy mesentry with gut, 1 single kidney with poor general condition), For uretero-lleal anaestomosis we used Bricker method in all cases.
\end{abstract}

Result: Mean OR time was 3:45 hours, blood loss average $350 \mathrm{ml}$, hospital stay after operation 9 days, enlarged pelvic lymph nodes were found in two cases. In follow up we found,stomal stenosis of cutaneous ureterostomy in 1 out of 3 cases, lleal conduit prolapse with para-stomal hernia in 1 out of 20 cases, stenosis at uretero-lleal anastomosis in 1 pt. .Distant recurrence occurred in two cases, one in Lt. Supraclavicular $L N$ and another in sacrum near SI joint. No local recurrence was found in any case.

Conclusion: Our experience on RC and all the three types of UD are safe and effective for patient and encouraging for us.

Bangladesh J. Urol. 2018; 21(2): 62-65

\section{Introduction}

Cystectomy nesessitates reconstruction of lower UT. Bladder cancer is the most common reason, other reasons are pelvic exenteration for other malignancies, birth defects, trauma, neuro-urological disorders etc. Ureterosigmoidostomy was the first widely used

1. Associate Professor, Department of Urology, NIKDU, Dhaka

2. Assistant Professor of Urology, NICRH, Dhaka

3. Registrar, NICRH, Dhaka

4. Assistant Professor, Sheikh Hasina Medical College, Jamalpur

5. Assistant Registrar, NICRH, Dhaka

6. Ex-Chairman and Professor of Urology, Uro Oncology, BSMMU, Dhaka

Correspondence: Dr. Md. Shawkat Alam, Associate Professor of Urology, Dhaka. Email: shawkat.alam@yahoo.com

Received: 9 August 2017

Accepted: 05 March 2018 diversion using the anal sphincter for continence. App. 50 yrs experience with this approach defined a series of complications that guided subsequent surgical progress. Subsequent surgical advances have led to major improvements in both functional outcomes and health-related quality of life (HRQOL). Radical Cystectomy $(R C)$ is an effective surgical procedure for muscle invasive bladder cancer (MIBC). Five years disease free survival after RCs are PT2 - 81\%, PT3a$68 \%$, PT $3 b-47 \%$, PT $4 a-44 \%$ respectively[ 1$]$. In this study early surgical \& oncological outcome have been assessed. Both continent and incontinent diversions are available for urinary reconstruction after RC. Orthotopic neobladders optimally preserve body image, while continent cutaneous diversions represent a reasonable alternative. Ileal conduits represent the most commonly performed urinary diversion. 
Patients \& methods: This study was conducted in the geneto-urinary oncology department of $\mathrm{NIRCH}$. A total of 24(N) patients underwent radical cystectomy with urinary diversion between December 2013 to June 2016. Age ranges from 41-69 years. Indications were T2HG for twenty cases and T1HG for four cases. Among the T1 tumours, one had early recurrence, one had numerous tumours and two had multiple tumours with concomitant CIS. Urinary diversion methods were: Orthotopic Ileal neobladder-1, Ileal conduit-20, Cuteneous Ureterostomy -3 (2 due to unhealthy mesentry with gut, 1 single kidney with poor general condition), For uretero-lleal anaestomosis we used Bricker method in all cases.

\section{Result:}

Mean OR time was 3:45 hours, blood loss average $350 \mathrm{ml}$, hospital stay after operation 9 days, enlarged pelvic lymph nodes were found in two cases. In follow up we found,stomal stenosis of cutaneous ureterostomy in 1 out of 3 cases, lleal conduit prolapse with para-stomal hernia in 1 out of 20 cases, stenosis at uretero-lleal anastomosis in $1 \mathrm{pt}$. .Distant recurrence occurred in two cases, one in Lt. Supraclavicular LN and another in sacrum near SI joint. No local recurrence was found in any case.
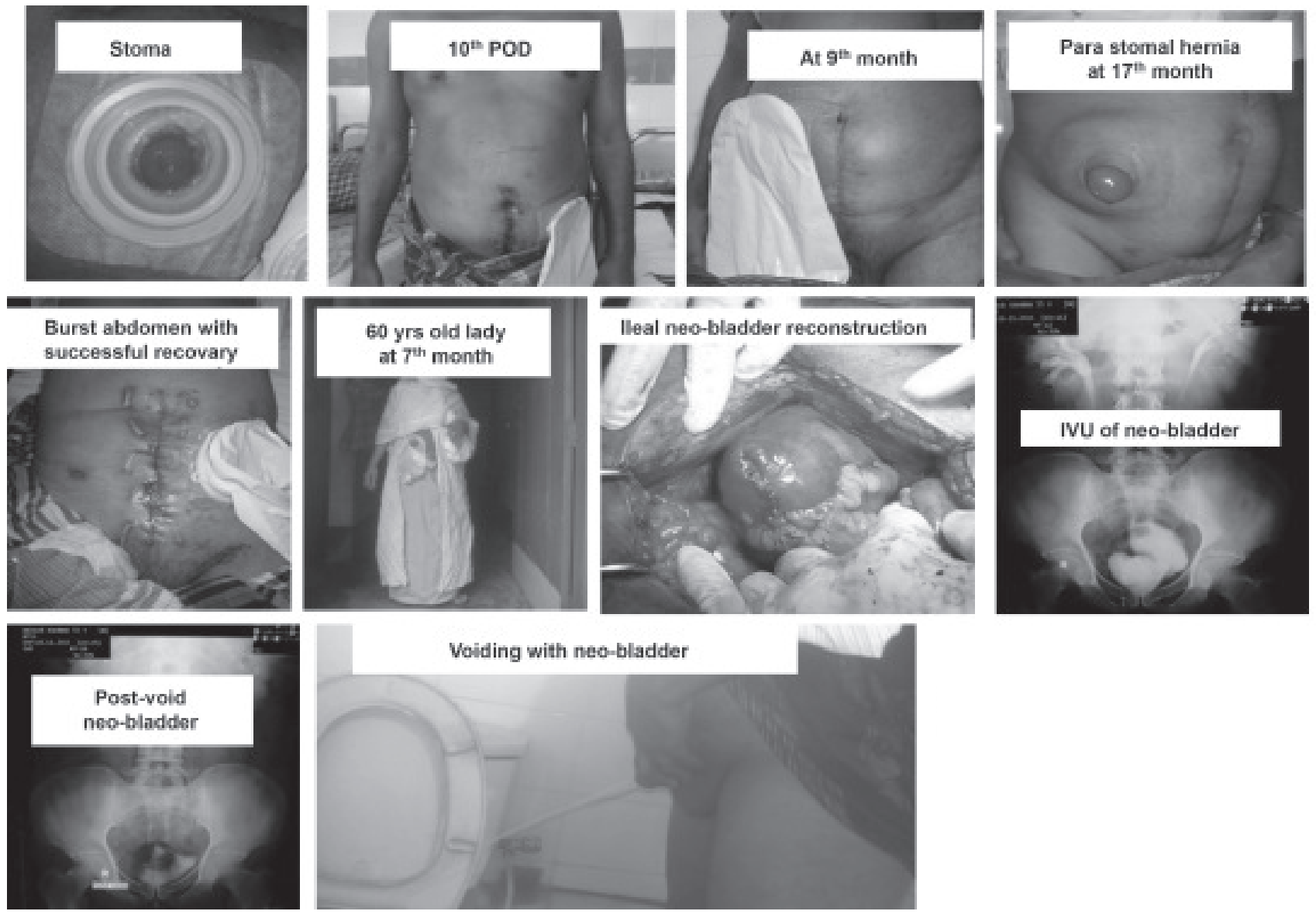

Figure: Surgical outcome at different stages

Table I

Patients characteristics

\begin{tabular}{|c|c|c|c|c|c|}
\hline$\overline{\mathrm{No}(\mathrm{N})}$ & M:F ratio & Age range & BMI & $\begin{array}{c}\text { T Stage \& } \\
\text { Grade }\end{array}$ & $\begin{array}{l}\text { PT Stage } \\
\text { \& Grade }\end{array}$ \\
\hline \multirow[t]{3}{*}{24} & $3: 1$ & $41-69$ & $17-41$ & T2HG-20 & T2HG-19 \\
\hline & & & & T1HG-04 & T1HG-04 \\
\hline & & & & & T3aHG-01 \\
\hline
\end{tabular}


Table-II

Issues affecting urinary diversion selection

\begin{tabular}{lccc}
\hline Cancer control & General health & Technical & HRQOL \\
\hline Risk of local recurrence & Functional status & Functioning urethra & Compliance \\
Previous pelvic radiation & Previous surgeries & Tumor location & Sexual function \\
Need for adjuvant therapy & Renal/hepatic function & Ability to Catheterize & Body image \\
Secondary malignancies & Medical co-morbidities & Mesentery length & Urinary function \\
Urethra or bladder neck involvement & Status of Gl tract & Bowel condition & Family support \\
\hline
\end{tabular}

Table-III

Comparison of complications in ileal conduits vs continent diversions

\begin{tabular}{llccc}
\hline Type of diversion & Reference & $\begin{array}{c}\text { No. of } \\
\text { patients }\end{array}$ & $\begin{array}{c}\text { Time from surgery, } \\
\text { months }\end{array}$ & \% Complications \\
\hline Ileal conduit & Pare kh et al.2000 & 81 & 19 & 22 \\
& Gburek et al.1998[3] & 66 & 20 & 18 \\
& Madersbacher et al.2003[4] & 131 & 98 & 66 \\
& Salam et al. 2013 & 422 & 38 & 29 \\
& NICRH 2016 & 24 & 28 & 20 \\
Continent diversion & 8 & 59.9 & 0 \\
& Shimogaki et al.1999 & 60 & 20.2 & 13 \\
& Ali-el-dein et al.1999 & 363 & 57 & $15.4-23.4$ \\
& Hautmann et al.1999[5] & 166 & 32 & $23.5-37.4$ \\
& Steven et al.2000 & 154 & 48 & 36 \\
& Salam et al. 2011 & 1 & June'15 & 0 \\
\hline
\end{tabular}

\section{Discussion:}

The primary goal of $\mathrm{RC}$ is control of the underlying tumour. Risk factors for urethral recurrence after RCmultifocal disease, carcinoma in situ, upper tract urothelial carcinoma, and involvement of the bladder neck or prostatic urethraThe reported incidence of urethral recurrence after $\mathrm{RC}$ ranges from 0 to $18 \%$, with a recent meta-analysis reporting $8.1 \%$ overall incidence. Most recurrences are detected d" 2 years after RC[2].

Factors Influencing Choice of diversion: The primary goals are lowest potential for complications and the highest HRQOL. The decision process is complex and involves consideration of issues related to cancer stage, patient co-morbidities, treatment needs, and patient desires related to HRQOL (Table 3). Elderly patients are usually offered primarily ileal conduits, whereas orthotopic neobladders tend to be reserved for younger, healthier patients. Recovery of continence after surgery may take longer in elderly pt. than in younger patients. Age is an important determinant of long-term reservoir capacity, nocturia, and continence status in patients with ileal neobladders. While patient preference is important, absolute and relative contraindications for the use of various bowel segments and continent urinary reservoirs do exist. Patients should be informed that intra-operative findings may dictate a change in the planned form of urinary diversion, e.g. positive urethral margin precluding orthotopic diversion.

Diversion-related complications: In ileal conduit diversion, four most common complications reported are pyelonephritis, ureteric obstruction, urinary calculi and stomal complications. The frequency of complications increased over time from $45 \%$ at 5 years to $94 \%$ at 15 years. Continent urinary diversions involve multiple suture lines, valve mechanisms, tapered limbs, and longer operative times than ileal conduits. They are subject to a higher incidence of urinary leaks in the early postoperative period and may be subject to pouch rupture at any time. 


\section{Conclusion:}

Our experience on RC and all the three types of UD are safe and effective for patient and encouraging for us. UD after RC, a complex process- every attempt to maximise HRQOL. Selection involves many different factors. More detailed analysis of HRQOL differences will require prospective studies with adequate baseline measures using validated instruments. The ideal urinary diversion should successfully preserve renal function while managing urinary outflow and minimizing morbidity to the patient. Much progress has been made in the field of urinary reconstruction since the introduction of uretero-sigmoidostomy. Newer urinary diversions are able to decrease the risk of secondary malignancy, provide continence, and preserve body image to a much greater extent. However, the quest for further improving urinary diversion should continues in an effort to benefit patients.

\section{References:}

1. Stein JP, Lieskovsky G, Cote R, et al. Radical cystectomy in the treatment of invasive bladder cancer: Long term results in 1054 patients. J Clin Oncol 2001; 1:666-75.

2. Bricker EM. bladder substitution after pelvic evisceration. Surg Clin North AM 150;30:1511-3.

3. Gburek BM Lieber MM, Blute MI, Compassion of studier ileal neobladder and ileal conduit urinary diversion with respect to preoperative outcome and late complications. J Urol 198;160:721-3.

4. Madersbacher S, Schmidt J, Eberle JM, et al. Long term outcome of ileal conduit diversion. $J$ Urol 2003;16:985-90.

5. Hautmann RE. Urinary diversion: lleal conduit to neobladder. J Urol 2003: 16: 834-42. 